\title{
Fair Use Rights in the Digital World: A Phenomenological Study of Instructional Technology Specialists
}

\author{
Turgay Alakurt ${ }^{1}$ \\ ${ }^{1}$ Department of Computer Education and Instructional Technology, Dumlupinar University, Kütahya, Turkey \\ Correspondence: Turgay Alakurt, Department of Computer Education and Instructional Technology, Dumlupinar \\ University, Kütahya, Turkey. E-mail: turgay.alakurt@dpu.edu.tr
}

Received: June 31, 2015

Accepted: August 17, 2015

Online Published: September 4, 2015

doi: $10.5430 /$ ijhe.v4n4p25

URL: http://dx.doi.org/10.5430/ijhe.v4n4p25

\begin{abstract}
The aim of this study is to reveal an insight into the awareness and experiences of IT specialists about fair use in Turkey. A phenomenological design was employed and the criterion sampling method was used in this study. A total of nine specialists volunteered to participate. The data were collected through semi-structured interviews. Information seeking behaviors of the participants in this study displayed the transformation in knowledge acquisition activities. Although ICT specialists have the ability to develop, operate and maintain ICT systems and tools, they are not required to develop e-content. The findings indicated that they actively use web repositories for the needs of digital content and a group of IT tools (e.g. LMS and CMS) for learning and learning management. On the other hand, the findings revealed that, even if they are qualified staff in educational technology and implementing effective policies regarding the technology integration into classroom, the majority of those interviewed had low level of awareness about fair use principles. These results provide potentially important implications for educational institutions developing efficient in-service programs to raise the awareness among faculty members and undergraduate students about copyright and fair use in higher education.
\end{abstract}

Keywords: Copyright, Fair use, Fair dealing, Higher education, IT specialist, Scholars

\section{Introduction}

Copyright is a legal term that defines the rights that are given to the owners of the works in return for their intellectual and artistic works (The World Intellectual Property Organization, 2015). It establishes an appropriate balance between the benefits of the owner of the work and the common good. This term, apart from the exclusive rights of the owner of the work, also includes the regulations for public access to the works protected by the copyrights and for the utility of these works for the common good. In this respect, with the copyright, the owner of the work is subject to some exceptions and limitations for the common good (Burk \& Cohen, 2001; Correa, 2002; MacKnight, 2000; Pistorius, 2006). These exceptions allowing limited use of a copyrighted work without prior notice and free of charge are called as "Fair use" or "Fair dealing". The roots of the principle of fair use date back to American copyright Law in 1841 (Marley, 1999). The written definition of fair use, on the other hand, was first included in American copyright law in 1976 (Part 107) (Bagley, 2007; Postigo, 2008). In the law, it is stated that the fair use of a copyrighted work, including such use by reproduction in copies or by any other means specified by this section, for purposes such as criticism, commentary, news report, teaching, scholarship, or research, should not violate copyrights. Moreover, it is also stated in the law that there are four factors that should be considered in order to decide whether a particular use is indeed fair use. These factors are:

1. The purpose and characteristics of the use: Benefiting from a work in educational and instructional processes or academic studies; usage of the work by non-profit educational institutions; encouragement of free discussions on the quality of the work (ex. News, criticism, commentary) and usage in order for developing general public comprehension on literary or art works (ex. Satire, parody) are considered as appropriate and permissible for fair use. However, the use of a work for commercial and entertainment purposes, profit oriented usage and usage with intention of deception are not considered as appropriate to fair use.

2. The nature of the copyrighted work: Benefiting from the works that are produced by spending less intellectual labor/ exertion are more suitable for fair use compared to benefiting from the works that are produced by 
spending more intellectual labor/exertion. For example; a professional video produced by a studio requires more intellectual labor/exertion in comparison with a video that is produced at home, individually.

3. The amount and substantiality of the portion taken: Taking less from a study is considered as appropriate for fair use. However, less does not always mean that it is appropriate for fair use. Another point which should be considered under this criterion is that the quoted part should not constitute the part which is called as "the heart" of the study. For example, sharing of the end part of the scene, "The Sixth Sense", where it is revealed that Bruce Willis turns to be dead, will lessen the commercial value of the movie.

4. The effect of the use upon the potential market: Under this factor, the potential market or value of the work is considered. For example, a teacher cannot copy a whole book for his students so that his students will not have to pay for it.

Within the framework of the law in which general fundamentals about fair use principles were determined, every case is handled in its special context by the federal courts. In order to decide whether a particular use is fair or not, the court should consider these four factors one by one (Correa, 2002; Pressman, 2008). No factor alone dictates whether a particular use is indeed fair use. Below is a related case and judgment example from a copyright case that took place in United States of America (Karjala, n.d.):

Leslie Kelly, who is a professional photographer, has photos which are protected by copyrights. She is keeping a few of these photos on her website and keeps them under protection with a license agreement. Arriba Software Company is running a search engine which presents the search results to its users as thumbnails. The company has built its database by copying photos from other web pages. By clicking on these small pictures, users are able to view a larger size of the same picture within the context of the company web site. Arriba Company was sued by Leslie Kelly because of copying her pictures without permission. The court has decided that the use of small sized pictures, thumbnails, does not contradict the license agreement of the pictures and does not create an obstacle in their commercial sales. It was stated that Arriba Company displayed a fair use. (Kelly v. Arriba, 336 F3d 811 (9C 2003)

In the case example above, two factors play very important roles in the court's decision of fair use: (1) the pictures were smaller and had lesser quality compared to the original photos - the usage had no effect on the commercial market of the work and (2) Arriba's use was significantly transformative - carrying an aim of usage for common good.

\subsection{Fair Use in International Agreements}

Bern Convention, the first multi-sided agreement with international quality regarding the protection of literary and artistic works, includes important regulations about fair use of the copyrighted works. Turkey joined the Bern Convention's 1948 text in 1952, and then sided with its latest version of 1979 in 1995. In Article 9(2) of the Bern Convention, there is a general guide, which is called as "three-step test". This guide helps the member countries determine their fair use principles. In essence, the scope and the availability of the principles are determined by the member countries' own regulations. This formulation is set out in similar terms in Article 5(5) of the Information Society Directive. The three conditions, namely (1) under certain special conditions, (2) no conflict with the normal exploitation of the work and (3) no unreasonable prejudice of the legitimate interest of the right holder are cumulative (COM, 2008; Hugenholtz \& Senftleben, 2011).

Agreement on Trade-Related Aspects of Intellectual Property Rights (TRIPs), the most comprehensive agreement up to now on intellectual property accepted internationally, also forces the member countries of World Trade Organization (WTO) to comply with the clauses of the Bern Convention. The "three steps test" in Bern Convention has been stressed and accepted in the 13th clause of the TRIPS agreement. Moreover, with the agreement, it is also aimed to reach common standards among the member countries and have common norms in terms of elimination of inner regulation differences, scope, and protection duration, allowed rights and gaining the formal rights. Turkey is one of the constituent members of WTO and a party to the WTO Agreement on Trade Related Investment Measures (TRIMS). In the review report regarding Turkey, which was completed in years 2000-2001, it was stated that regulations were in compliance with the TRIPS Agreement and that they carry the required basic standards. Within the frame of fair use principles determined by Bern Convention and TRIPS Agreement, in the parts between Turkish copyright law's 30th and 40th clauses, considering the common good, some rights of the owners of the works has been limited and users were allowed some exceptions (Turkish Ministry of Culture and Tourism, 2006). Yet, in using these exceptions, there are two important criteria that are mentioned in the law. These are: (1) to a degree that the final aim should justify and (2) in cases that the exception harms the legal benefits of the owners of the works 
without any excuse or contradicts with the normal use of the works. Besides, when the exceptions, which the users are allowed regarding the fair use, are examined, it is seen that the purpose of using an intellectual or artistic work is another important criterion. The similarities of the principles of fair use within the frameworks of American, European and Turkish copyright laws are presented in Table 1.

Table 1. Fair Use Factors

\begin{tabular}{|c|c|c|}
\hline US copyright law (Part 107) & $\begin{array}{l}\text { EU copyright law (Three step test } \\
\text { formulates the EU copyright } \\
\text { framework, article } 5(5) \text { of the } \\
\text { Directive) }\end{array}$ & $\begin{array}{l}\text { Turkish copyright law (Law number } \\
\text { 5846) }\end{array}$ \\
\hline $\begin{array}{l}\text { The purpose and characteristics } \\
\text { of the use }\end{array}$ & Certain special cases & Purpose \\
\hline $\begin{array}{l}\text { The nature of the copyrighted } \\
\text { work }\end{array}$ & $\begin{array}{l}\text { No conflict with the normal } \\
\text { exploitation of the work }\end{array}$ & $\begin{array}{l}\text { In an amount justified by the } \\
\text { purpose }\end{array}$ \\
\hline $\begin{array}{l}\text { The amount and substantiality } \\
\text { of the portion taken }\end{array}$ & $\begin{array}{l}\text { No unreasonable prejudice to right } \\
\text { holders' legitimate interests }\end{array}$ & $\begin{array}{l}\text { The use must not prejudice the } \\
\text { legitimate interests of the author or }\end{array}$ \\
\hline $\begin{array}{l}\text { The effect of the use upon the } \\
\text { potential market }\end{array}$ & & $\begin{array}{l}\text { conflict with normal exploitation of } \\
\text { the work }\end{array}$ \\
\hline
\end{tabular}

As can be seen in Table 1, similar criteria regarding fair use are considered and stressed in national and international agreements. The basis of these criteria is founded on the purpose of use, avoidance from excessive use and harming the benefits of owners.

\subsection{Fair Use in the Classroom}

The concept of fair use and its application in educational environments, especially in higher education, is evaluated on the basis of creating the knowledge and technology, and spreading them to the whole society and that is the basic duty of higher education. In order to carry out this duty, in their studies, learning environments, and teaching methods, scholars are using various information sources, information types and contents. However, it is expected to ensure that such usages should not cause copyright infringement or unreasonable limitations. Hence, scholars, in order to produce creative and unique works in their studies, should have skills to freely obtain, analyze, use and exchange information by considering the fair use of the works which are protected by copyrights. The right of fair use, which is protected by national and international agreements, enables the scholars to use increasing information sources and developing information technologies within the dynamic nature of education processes, and at the same time, to constitute a more flexible copyright system that meets changing human needs. Thus, the scholars and students can access the copyrighted works within the legally determined reasonable limits, create new works over the old ones, and discover new ideas on a wider range. However, the use of a work for educational purposes cannot solely be considered as fair use. This situation only represents an act of the framework of fair use principles (Desmarais, 2001).

\subsection{Research Questions}

This study tried to answer the following research questions:

1) To what extent are IT specialists aware of "fair use"?

2) How do they use the application of fair use principles in their studies?

\section{Methodology}

This study was carried out by using a qualitative research design with a phenomenological method of inquiry, since the main interest was to explore and obtain experiential information from experts who have rich knowledge in the field of ICT in education. I had a close view to their understanding and articulating common or shared experiences about fair use.

\subsection{Participants}

To develop pragmatic insights regarding the research questions, a qualitative research design was employed. I identified some specific cases using criterion sampling. In this sampling method, criterion or criteria can be formed by the researcher (Patton, 2014). I defined two criteria in forming the study group. The first criterion was that the participants should have had their PhDs in the field of educational technology. The key factor in determining this 
criterion was that graduate programs in educational technology are designed to prepare graduate students as instructional designer, instructional technology supervisor, e-learning developer, curriculum consultants, HR training specialist and technology specialist for a school, county, or district in instructional technology education. Graduates have high-level ICT skills and knowledge. Associated with these employment opportunities are a variety of job titles. In this study, the title, instructional technology (IT) specialist was adopted and used in general. The second criterion was that the participants should have had their PhDs in the last five years. The key factor in determining this criterion was that I specifically focused on participants' doctoral studies since a doctoral study is an applied research on a problem and a researcher are likely to arrive with an extensive knowledge during his/her doctoral studies. I invited 19 experts to attend semi-structured interviews. Interviews were conducted with nine volunteer participants. All participants are currently working at state universities in Turkey. They are either responsible for developing researches in the area of educational technology in the faculty of education or executing designs, product images and other graphics in the distance education center. The interview questions in the form are presented below:

1) When you think about the works you used in your study, tell me about the information sources you used to reach these works?

2) What kind of works did you used in your study?

3) How does it affect your use of a work if that work is protected by copyrights?

4) What did you pay attention for when you were benefiting from works? Give examples in accordance with your use of printed or digital sources?

5) Tell me about the factors you would consider when using a copyrighted work? In which situations and how would it be proper to use such works?

6) Were there any works that you hesitate to use or abandoned to use in your study? Tell me why?

\subsection{Data Collection and Analysis}

In order to determine IT specialists' awareness and experiences about fair use and use of fair use principles in their works, a semi-structured interview form was prepared by the researcher. As Yildırım and Şimşek (2011) stated, the questions were kept easy to understand, focused open-ended, and not multi-dimensional. The prepared draft form was presented to one assessment and evaluation expert and two IT specialists for previewing. After receiving the feedback from the experts, a pilot study was carried out with another IT specialist. After the necessary amendments were done on the interview form following the pilot study, the form was once more sent to the same experts for previewing. After receiving the feedback from the experts and amendments, the form was given its final shape and made ready for the actual application.

In this study, the "work" refers to any intellectual or artistic product bearing the characteristics of its author, which is deemed a scientific and literary or musical work or work of fine arts or cinematographic work. The interviews were planned to be carried out by phone. In the process of gathering information, two IT specialists stated that due to their workloads, they would like to give written answers to the interview questions. These participants sent their views to the researcher in written form. Seven of these interviews were recorded with digital voice recording device. Descriptive analysis was used to resolve the data. The raw data were resolved in a way that they would contain the answers of research questions on the basis of the sentences under three main categories: basic information sources, types of works (audio visual elements etc.) and factors that affect using a copyrighted work. Data were analyzed by the researcher himself and separately by an expert from another field. NVivo 8.0 qualitative data analysis package program was used to analyze data. Nvivo is a powerful tool for qualitative analysis. The researcher reread each interview transcript in the program and classified them to determine the related codes based on their similarities and differences. The related codes were put together and certain categories were obtained.

Currently, the researcher is giving courses and lectures on computer ethics and has spent more than ten years researching the topic with both qualitative and quantitative methods. Researcher's personal experiences and insights were an important part of the study. To ensure trustworthiness, the researcher rigorously adhered to procedures outlined by Yıldırım and Şimşek (2011). The researcher read participants' PhD theses before interviews and took field notes during the interviews. He also asked a few participants to review their transcript as a form of member checking and discussed the data and emergent findings with other scholars. Additionally, data collection occurred over three months. It enabled the researcher to increase the validity of the findings. 


\section{Findings}

\subsection{Basic Information Sources}

In the interviews, the participants were asked to state through which ways they had access to the works that they used in their studies, and what sources/tools they used in doing so. All of the participants said that they use web-based electronic resources. They also stated that digital library or digital repository (online databases as well as e-journals and e-books) play a leading role in accessing the required information. However, some participants mentioned that when they did not have permission to access a full text material or multimedia contents through their own university library system, they might get access to such contents via databases to which another university was a subscriber. One participant stated this situation as:

I actively used university database, especially the database of A University. I can say that $70 \%$ of the sources I accessed were from these databases. [Participant 2]

Most of the participants stated that apart from online databases, they use Google Scholar, Google Books services, and national thesis database (Responsible institution is The Council of Higher Education) respectively. One of the participants stated that he sometimes searches databases through Endnote program.

I made quite use of online academic research databases of the university. Generally, EbscoHost, Science Direct, Ebrary databases. [Participant 9]

... apart from that, I tried to benefit from Google Scholar. [Participant 2]

In accordance with their opinions on how they access the works, it was seen that the participants prefer electronic sources rather than printed ones. They also use various online tools and devices for accessing. Moreover, it is understood from the statements of the participants that they might face with a lack of institutional subscriptions so they get in touch with employees from other universities and use the databases that those universities are subscribed.

\subsection{Types of Works}

Most of the participants stated that they did not develop or use multimedia contents in their studies, but did text based studies. Two participants, on the other hand, stated that they used videos and visuals. Another participant, who stated that he developed the contents of his studies, explained this situation as:

...I developed $80 \%$ - 90\% of the visuals. I took some of the videos from Youtube. I mean, I developed most of the other files, more or less, myself. [Participant 8 ]

Examples from the statements of some participants about the visual-audio elements which they use in their works are given below:

I did not develop anything. We have already worked on this developed platform and in it they especially carried out situation discussions. These text based contents were ready. Therefore, I did not constitute anything but used what already existed. [Participant 5]

There was text in the web site I developed...Apart from that; there were no graphics, pictures etc. I mean, graphically small arrows and the like...things that are present in every application. [Participant 4]

According to the statements of the participants, they actively use ready systems such as learning management systems and content management systems. Even they have the ability to develop, operate and maintain ICT systems, they frequently carry out text based studies on ready platforms such as LMS/CMS for learning and learning management. They also indicated that too much content on the web is relevant and it is not a necessity for them to develop a specific local content.

\subsection{Factors that Affect Using a Copyrighted Work}

I specifically asked the participants in what situations and how they use works in their studies. All of the participants said that they absolutely cite the source. Some of them also stated that they asked for permission from the owner of the work and completed all the permission procedure before they use the work in their studies. Besides, five of the participants strictly stated that they would never use a work if they do not have the owner's permission.

If I have to use I may want to reach the owner of the work. I mean, by sending an e-mail explaining to the owner on what subject and in what way I am going to use, I mean how I am going to use, and by consulting if there is any objection for my using, I would try to ask for permission, or I may ask for the permission to use the whole work. I would also state that I will cite appropriately, without any problems, his work. [Participant 5] 
Most of the participants interviewed stated that they primarily prefer nonprofit software programs that enable some rights to the users under certain circumstances, works and contents (exp. free of charge, sharable, creative commons etc. licensed). One participant, on the other hand, stated that he used commercial software in his study, and another participant stated that he primarily preferred free programs but as these softwares did not meet his needs, he used licensed, commercial software programs.

Especially, in terms of software lately, you know, any software is at least for 30 days. Giving its full features. I quite prefer those kinds of things. [Participant 7]

Besides, three participants stated that it would not cause inconveniency if they use works for educational purposes and not for commercial use. Examples regarding the statements of these participants are given below:

If the study I carry out is not commercial but a study for educational purposes and for public, if it is a study for common good, I would use it as I do not think it would cause any problem in terms of copyrights. [Participant 2]

As long as I do not pursue a commercial aim, I think that I can handle this by quoting without any problem. [Participant 5]

Two participants, on the other hand, stated that they consider taking less from printed or digital works. Moreover, one of these participants stated that he also advises his students to follow the same manner in such uses in instructional processes.

Other printed works or such materials, you know, for example we advise that they should limit photocopying at a certain point. [Participant 7]

If necessary, we cut and use 2-3 minutes of a copyright protected video. [Participant 6]

In accordance with the views of the participants regarding the situations and how they use the copyrighted works, all the participants expressed the need for citing sources. But interestingly a majority of the participants highlighted that they will never use a work without permission. Furthermore, most of the participants mentioned that they use free contents and softwares which are free of charge and available on the Web. In three cases, participants expressed that they could use copyrighted works for instructional purposes without any commercial aim. Two participant also pointed out that they were likely to consider taking less.

\section{Discussion}

The results of this study depend on a very small and specific group of nine ICT specialists, which is sometimes a cause for criticism in a qualitative research (Kidd, 2002). Due to the restrictions of the small number caused by the sampling, I did not aim to generalize my findings. I, nevertheless, think that the findings and conclusions can be transferable to other settings which are similar to the one where the study was conducted. For example, the findings provide insights into the awareness and experiences of not only IT specialists, but also academics in all academic disciplines about fair use.

The findings of the study reveal the transformation in information seeking behaviors and knowledge acquisition activities. In today's society, online databases and google are the major modes of accessing scientific knowledge. Baby boomers have already began to retire (Bingham \& Conner, 2010) and we confront a new generation who have come into new digital age with comprehensive technology competencies.

One particularly interesting finding of this study is that none of the participants expressed the three-step test, framework of fair use principles and national laws or international regulations regarding the fair use. The results showed that ICT specialists are not well aware of fair use principles protected by national and international regulations in effect on the protection of intellectual property rights. Although a few participants stated the key aspects of fair use such as educational purposes, amount of the portion taken and citing, as aforementioned, no one factor alone dictates whether a particular use is indeed fair use. In order to determine whether a particular use is or is not a fair use, we need to apply all the factors (Bagley, 2007; Leary \& Parker, 2011; Wilson, 2005).

New competences required in the digital age are evolving. In an updated study of instructional design sufficiency by International Board of Standards for Training, Performance and Instruction (IBSTPI) (2012), it is stated that all instructional designers should "identify and respond to ethical, legal, and political implications of design in the workplace." Similarly, International Society for Technology in Education (ISTE) (2008) states that all teachers should "understand local and global societal issues and responsibilities in an evolving digital culture and exhibit legal and ethical behavior in their professional practices." An "unfair use" of copyrighted materials may cause unwanted situations like suing that can be initiated by the owners of the works for both the violating parties and 
those who assist in this violation; like individuals, universities, internet service providers etc., real or legal entities (MacKnight, 2000; Wilson, 2003;). On the other hand, as Erdem (2012) stated, faculty members should comply with scientific ethics and be a role model for their colleagues and students. Taking less from a copyrighted work is always considered as appropriate to fair use. However, there is no legal text as an answer to the question of "how much?" In a world of rapid and unpredictable technological development, it is also hard to reconcile with a generally recognized legal regulations. For that reason, the awareness of scholars and students regarding copyright and fair use should be raised. In this context, I believe that in-service programs can be structured to help faculty members improve constantly their knowledge about copyright and fair use.

Some suggestions were brought forward in accordance with the results of the research. Certain colleges and universities around the world offer their students an opportunity to study computer ethics under various course names such as "Computer Ethics", "Ethical Issues in Computer Science", "Cyber Law and Ethics", "Business and Computer Ethics" and "Computers, Ethics, and Society". Besides that, common issues of computer ethics are discussed in some related courses, such as "Management Information Systems". First of these suggestions includes the extension of these courses to all faculties as shared compulsory courses. I believe that such a regulation will help increase the knowledge and awareness of the students in undergraduate and graduate levels, especially in developing countries like Turkey. It will also help develop scientific research and publishing ethics in higher education. Secondly, the results of this study suggest that digital divide may raise ethical issues. Since some participants have trouble getting access to the online resources off campus and on campus, they are using friends' accounts getting access to the databases to which another university was a subscriber. As Mason (1986) stated, I believe that access is still one of the major ethical issues of the knowledge age in Turkey. For this reason, equal access right to the same databases for all the registered students in state or foundation universities can be provided and a common software depot which can be used free of charge can be constituted in the structure of national higher education. Additionally, free and open-source software can serve as a viable alternative to proprietary software. Educational institutions wish to use, contribute and develop open-source software. Such an approach can prevent not only unethical behaviors but also ethical and legal problems. It also pave the way for developing new technologies with financial support to the technology research and development centers in educational institutions or software companies by determining the national educational needs. Finally, the sensitivity for respecting works and labor should be taught to children at early ages. To this end, seminars can be organized in cooperation with the Ministry of Education.

\section{References}

Bagley, A. W. (2007). Fair use rights in a world of the broadcast flag and digital rights management: do consumers have a chance? University of Florida Journal of Law \& Public Policy, 18(1), 115-135.

Bingham, T., \& M. Conner (2010). The New Social Learning: A Guide to Transforming Organizations Through Social Media. San Francisco, CA: Berrett-Koehler Publishers.

Burk, D. L., \& Cohen, J. E. (2001). Fair use infrastructure for copyright management systems. Harvard Journal of Law and Technology, 15, 41-83.

COM (2008) 466/3. Green paper; Green paper copyright in the knowledge economy, Brussels, Commission of the European Communities.

Correa, C. M. (2002). Fair use in the digital era. International Review of Industrial Property and Copyright Law, $33(5), 570-585$.

Desmarais, N. (2001). Copyright and Fair Use of Multimedia Resources. Acquisitions Librarian, 13(26), 27. http://dx.doi.org/10.1300/j101v13n26_03

Erdem, A. R. (2012). Ethics Education in Training of Scientists. Journal of Higher Education and Science, 2(1), 77-81. http://dx.doi.org/10.5961/jhes.2012.030

Hugenholtz, P. B., \& Senftleben, M. (2011). Fair Use in Europe: In Search of Flexibilities. http://dx.doi.org/10.2139/ssrn.1959554

International Board of Standarts for Training, Performance and Instruction. (2012). Instructional Designer Competencies. Retrieved January 20, 2015, from http://ibstpi.org/instructional-design-competencies/.

International Society for Technology in Education. (2008). Standards for Teacher. Retrieved January 20, 2015, from http://www.iste.org/docs/pdfs/nets_for_teachers_2000.pdf.

Karjala, D. S. (n.d.). Kelly v. Arriba, 336 F3d 811 (9C 2003). Retrieved January 22, 2015, from http://homepages.law.asu.edu/ dkarjala/cyberlaw/KelllyvArriba\%289C2003\%29.htm. 
Kidd, S. A. (2002). The role of qualitative research in psychological journals. Psychological Methods, 7, 126-138. http://dx.doi.org/10.1037/1082-989X.7.1.126

Leary, H., \& Parker, P. (2011). Fair Use in Face-to-Face Teaching. TechTrends: Linking Research \& Practice to Improve Learning, 55(4), 16-18. http://dx.doi.org/10.1007/s11528-011-0506-8

MacKnight, C. B. (2000). An overview of copyright law and distance education. Journal of Computing in Higher Education, 12(1), 107-120. http://dx.doi.org/10.1007/BF03032716

Marley, J. L. (1999). Guidelines Favoring Fair Use: An Analysis of Legal Interpretations Affecting Higher Education. Journal of Academic Librarianship, 25(5), 367. http://dx.doi.org/10.1016/S0099-1333(99)80055-X

Mason, R. O. (1986). Four ethical issues of the information age.Mis Quarterly, 5-12. http://dx.doi.org/10.2307/248873

Patton, M. Q. (2014). Qualitative Research \& Evaluation Methods: Integrating Theory and Practice, SAGE Publications.

Pistorius, T. (2006). Copyright in the Information Age: The catch-22 of digital technology. Critical Arts, 20(1), 47-61. http://dx.doi.org/10.1080/02560040608557776

Postigo, H. (2008). CAPTURING FAIR USE FOR THE YOUTUBE GENERATION: The Digital Rights Movement, the Electronic Frontier Foundation and the user-centered framing of fair use. Information, Communication \& Society, 11(7), 1008-1027. http://dx.doi.org/10.1080/13691180802109071

Pressman, R. R. (2008). Fair Use: Law, Ethics and Librarians. Journal of Library Administration, 47(3/4), 89-110. http://dx.doi.org/10.1080/01930820802186423

The World Intellectual Property Organization. (2015). Copyright. Retrieved January, 20, 2015, from http://www.wipo.int/about-ip/en/copyright.html.

Turkish Ministry of Culture and Tourism. (2006). Saylsal Haklar Yönetimi (DRM) [Digital rights management]. Retrieved January, 15, 2015, from http://www.bilgitoplumu.gov.tr/wp-content/uploads/2014/04/Eylem20_Sayisal_Haklar_Yonetimi.pdf

Wilson, L. (2003). The Copyright Guide: A Friendly Handbook to Protecting and Profiting from Copyrights: Allworth Press.

Wilson, L. (2005). Fair Use, Free Use, and Use by Permission: How to Handle Copyrights in All Media. Allworth Press.

Yıldırım, A., \& Şimşek, H. (2011). Sosyal Bilimlerde Nitel Araştırma Yöntemleri [Qualitative research in social science]. Ankara: Seçkin Yayınları.

\section{Notes}

Note 1. Because of the small number of participants, a conscious choice was made to protect identity disclosure in the quoted information and given demographics. 